\title{
QUILOMBO INTELECTUAL, INFORMAÇÃO ÉTNICO-RACIAL CIENTÍFICA E A VALORIZAÇÃO INTELECTUAL DA POPULAÇÃO NEGRA
}

\author{
QUILOMBO INTELECTUAL, SCIENTIFIC ETHNIC- \\ RACIAL INFORMATION AND THE INTELLECTUAL \\ VALUE OF THE BLACK POPULATION
}

\author{
Franciéle Carneiro Garcês da Silva ${ }^{a}$ \\ Lindiwe Sophia Oliveira Fideles ${ }^{b}$
}

\begin{abstract}
RESUMO
Objetivo: Analisar o papel da página Quilombo Intelectual para a promoção das discussões sobre questões étnico-raciais e valorização intelectual da população negra, via disseminação da informação étnico-racial científica. Metodologia: Trata-se de uma pesquisa de cunho documental, exploratório e descritivo, na qual foram analisadas as postagens publicadas na página do Quilombo Intelectual no Facebook no período de janeiro de 2020 a junho de 2021. Resultados: Ao total, foram coletadas e analisadas 618 publicações, categorizadas conforme os modelos de Abreu (2013) e Corrêa e Silva (2017). A partir dos modelos, foram elaboradas quatro categorias principais, a saber: informação étnico-racial científica e os quadros "Momento Griôt", "Encontro com o/a autor/a" e "Tenha na sua estante". Conclusões: A página Quilombo Intelectual promove fontes de informação científica e de cunho étnico-racial, as quais corroboram para: (i) o conhecimento do estado da arte sobre o tema em diversas áreas do conhecimento; (ii) a promoção da identidade étnico-racial da população negra; (iii) o conhecimento dos aspectos históricos, culturais, políticos e educacionais da referida população; (iv) o combate às informações pré-concebidas ou equivocadas, via ciência; (v) e, por fim, valoriza pesquisadores(as) negros(as) e de outros pertencimentos étnicos que abordam e discutem as relações étnico-raciais.
\end{abstract}

Descritores: Quilombo Intelectual. Facebook. Informação étnico-racial científica. População negra.

\section{INTRODUÇÃO}

Ao longo da história, em diferentes lugares do mundo, diversos autores e

\footnotetext{
a Doutoranda em Ciência da Informação na Universidade Federal de Minas Gerais (UFMG). Email: francigarces@yahoo.com.br

b Mestranda em Ciência da Informação na Universidade Federal da Bahia (UFBA). E-mail: fideleslindiwe@gmail.com
} 
autoras negras têm defendido a importância da biblioteca e da informação para transformação das realidades sociais de populações historicamente marginalizadas, como as negras, indígenas, LGBTQIA+, ciganas, entre outras.

No período pós-abolição nos Estados Unidos, as comunidades negras foram impedidas de ter acesso à biblioteca, seja por conta de leis segregacionistas, seja pela localização da biblioteca, ou pelo fato dessas comunidades não serem alfabetizadas e não conseguirem realizar a leitura dos materiais acessados (PORTER, 1938).

No Brasil, a história da biblioteca e da Biblioteconomia está vinculada a um espaço elitizado e de promoção do pensamento hegemônico, assim como as primeiras legislações criadas durante e após a abolição da escravatura colocavam as pessoas negras fora dos bancos escolares e, por consequência, impediam o seu acesso à informação, à biblioteca e ao livro. Ademais, foram realizadas políticas epistemicidas do conhecimento negro dentro do ambiente científico e bibliotecário, bem como de acesso à informação sobre sua história, memória e sociabilidades (SILVA, 2020). Nesse sentido, Gomes aponta que:

[...] é necessária uma sensibilização sobre o processo de exclusão social e racial para que as/os profissionais da informação ampliem e modifiquem sua atuação, buscando novas fontes do saber e do conhecimento, entrando em contato com movimentos sociais, coletivos negros, ações de promoção de capacitação profissional pra implementação do conteúdo histórico e cultural afro-brasileiro. (GOMES, 2016, p. 748).

Nas últimas décadas, legislações como as Leis Federais no 10.639/2003 e 11.645/2008 permitiram alguns avanços, dentre os quais a obrigatoriedade do ensino da história e culturas africanas, afro-brasileiras e indígenas e o aumento da produção científica produzida por e sobre a população negra e outras colocadas à margem (BRASIL, 2003; 2008).

Com o advento das tecnologias da comunicação e informação, outras formas de reparar o período em que as pessoas negras não tiveram acesso à informação estão sendo pensadas e, com o surgimento das mídias sociais, permitiu-se refletir sobre os modos de recuperar, selecionar, filtrar e disseminar a informação de forma seletiva e direta para as populações marginalizadas. 


\section{FONTES DE INFORMAÇÃO NA CIÊNCIA DA INFORMAÇÃO}

No que concerne aos estudos sobre fontes de informação no campo biblioteconômico-informacional brasileiro e sua relação com as questões étnicoraciais, populações negras e outras colocadas à margem, algumas pesquisas serão aqui evidenciadas. A primeira delas, é o artigo de Oliveira e Aquino (2012) em que $o$ autor e a autora conceituam:

[...] informação etnicorracial como sendo todo elemento inscrito num suporte físico (tradicional ou digital), passivo de significação linguística por parte dos sujeitos que a usam, tendo o potencial de produzir conhecimento sobre os aspectos históricos e culturais de um grupo étnico na perspectiva de sua afirmação na diversidade humana. (OLIVEIRA; AQUINO, 2012, p. 487).

No artigo de Paiva (2014), a autora apresenta o conceito de fonte de informação indígena a partir de um estudo das narrativas do povo Potiguara, indígenas que habitam o litoral setentrional da Paraíba, Brasil. Paiva (2014) afirma que a informação indígena se enquadra na informação étnico-racial. A autora amplia a concepção de fonte de informação no campo da Ciência da Informação apontando, inclusive, que as fontes de informação indígenas podem ser classificadas como fontes primárias e especializadas.

Santos e Aquino (2016) estabelecem a relação entre a Ciência da Informação e os Estudos Culturais. Segundo elas, é na abordagem sociocultural do fenômeno informacional que se inserem as fontes de informação étnicoraciais "enquanto artefatos enunciadores da cultura afrocêntrica" (SANTOS; AQUINO, 2016, p. 44). Afirmam ainda que as fontes de informação de cunho étnico-racial colaboram para minimizar práticas discriminatórias. Em complemento, Silva e Aquino (2014) inferem que tais fontes permitem que os sujeitos e grupos etnicamente invisibilizados possam ter informação e compreensão sobre seus direitos e deveres, sobre processos históricos e cotidianos de exclusão que os subordinam, dominam e afastam do pleno exercício da cidadania.

Outros estudos sobre fontes de informação para populações colocadas em situação de marginalização serão destacados. Vale e Vitorino (2019) se propõem a analisar as fontes de informação online no atendimento às 
necessidades de pessoas LGBTQIA+ nas áreas de educação e cuidados pessoais, geridas respectivamente pela TV Escola e pelo Projeto Práticas Corporais da Universidade Federal de Santa Catarina. O estudo concluiu que as duas fontes são confiáveis e pertinentes às necessidades de informação da população LGBTQIA+.

O artigo de Tonin e Souza (2014) apresenta a biblioteca prisional como uma instituição com a responsabilidade social de promover o acesso à informação. Nesse sentido, a autora e o autor abordam a importância de, para além da disponibilização das fontes de informação aos usuários apenados, refletirmos sobre o conteúdo informacional dessas fontes.

Retornando às fontes de informação étnico-racial, podemos citar como exemplos contidos na web, o projeto Mulheres Negras na Biblioteca ${ }^{1}$, cujo trabalho acontece dentro e fora das mídias sociais visando defender e incentivar a inclusão e a leitura de obras de autoria de mulheres negras em bibliotecas e espaços informacionais.

Os Núcleos de Estudos Afro-brasileiros (NEAB) são outro exemplo de fonte de informação étnico-racial, conforme o estudo de Andreia Sousa da Silva e César Karpinski (2018). A autora e o autor analisaram as publicações de seis páginas de NEABs no Facebook com o intuito de conhecer as informações disponibilizadas e a influência do Núcleo nas mídias. Concluíram que as informações disseminadas pelas páginas são significativas para as pessoas pesquisadoras e comunidade, haja vista que compartilham "informações relacionadas à história, cultura e memória africana e afro-brasileira, a situação do negro no Brasil e no mundo, as relações raciais, além de dados relacionados à legislação brasileira e acontecimentos atuais" (SILVA; KARPINSKI, 2018, p. 287). Para as pessoas autoras, a presença digital dos Núcleos e de suas atividades podem ser ferramentas para auxiliar na apropriação, empoderamento, uso e fonte de informações étnico-raciais, sobretudo no fortalecimento da memória, história e sociabilidades da população negra brasileira e suas demandas informacionais (SILVA; KARPINSKI, 2018).

\footnotetext{
${ }^{1}$ O projeto pode ser conhecido por intermédio de sua página no facebook acessível pelo link: https://www.facebook.com/mulheresnegrasnabiblio. Acesso em: 20 jun. 2021.
} 
As fontes de informação especializadas em africanidades foram identificadas no artigo de Wellington Marçal de Carvalho, Argelânia Rezende e Gabrielle Mendonça Rodrigues Gomes (2019), que resultou na seleção de 19 fontes de informação associadas à África ou de origem africana sobre diversas áreas e conteúdos, encontradas a partir do estabelecimento de três estratégias de busca diferentes. O termo "Africanidades" "quer traduzir a multiplicidade cultural do continente africano e enfatizar a existência de culturas diferentes e não de uma cultura única" (CARVALHO; REZENDE; GOMES, 2019, p. 178). Na referida pesquisa, as pessoas autoras apresentam critérios para identificar e descrever fontes de informação, assim como caracterizaram as fontes em africanidades em quatro categorias, a saber: a) Fontes de Informação Social e de Humanidades: que são informações de cunho interdisciplinar de e sobre África publicadas por africanos sobre educação, memória, cultura, história, geografia, entre outros. Dentre elas, o African Online Journal (AJOL), Slave Voyages e Portal de Memórias de África e do Oriente; b) Fontes de Informação de Finanças, Estatística e Indicadores Econômicos: se referem às informações sobre economia, finanças e estatísticas, em especial a produção sobre mercado de trabalho, ciência e negócios. Como exemplo são citadas o African Business Guide, da Library of Congress e Data Bank Africa, do The World Bank, além de outras fontes; c) Fontes de Informação para o Desenvolvimento Ambiental Sustentável, as quais são referentes ao meio ambiente e desenvolvimento ambiental com temas como crescimento econômico, migração, agricultura, biologia, dentre outros. São exemplos, a The Essential Electronic Agriculture Library e The Nordic Africa Institute; d) Fontes de Informação em Saúde, das quais o African Index Medicus Database é analisado por se tratar de uma fonte que promove acesso a informações sobre medicina, pediatria e saúde no contexto africano. As fontes de informação em africanidades são relevantes para pessoas interessadas em recursos e conteúdos informacionais sobre o tema e para os próprios profissionais da informação que atuam na formação e disseminação de recursos informacionais em acervos (CARVALHO; REZENDE; GOMES, 2019).

O podcast como fonte de informação étnico-racial tem aberto espaço para 
discussões diversas com uma linguagem simples que retoma o rádio como meio de comunicação, dessa vez, em formato digital. No artigo de Silva e Ferreira (2019), a autora e o autor concluem que o podcast:

\begin{abstract}
se trata de uma ferramenta informacional que pode ser consultada/ouvida de maneira flexível e como aparato pedagógico em ambientes educacionais e de formação profissional ou não. É um instrumento flexível que pode ser utilizado em sala de aula, como também pode ser disponibilizado online em ambientes informacionais e de pesquisa como biblioteca. (DILVA; FERREIRA, 2019, p. 116).
\end{abstract}

No campo da Biblioteconomia existem podcast que não são específicos das relações étnico-raciais, mas apresentam participações de estudiosos do campo dos Estudos Negros em Biblioteconomia e Ciência da Informação (BCl). É o caso do Biblioteco PodCast ${ }^{2}$, produzido pela Liga Bibliotecária, criado e conduzido por pessoas bibliotecárias, o Raphael Cavalcante e a Andréia Sousa da Silva. Nesse podcast há episódios com temas como "Decolonialidades", com a presença do pesquisador e bibliotecário, Ueliton Santos Alves; discutindo sobre Maria Carolina de Jesus, como o pesquisador e bibliotecário, Bruno Almeida dos Santos, assim como as escrevivências da escritora Conceição Evaristo e da bibliotecária negra e primeira presidenta da American Library Association, Clara Stanton Jones, com a presença das bibliotecárias Elisangela Gomes e Franciéle Garcês. Outro caso é o podcast Farol - Conexões da Informação ${ }^{3}$, uma criação do Centro Acadêmico de Biblioteconomia, Arquivologia e Museologia, coordenado por Fabiano Corrêa, Leolíbia Linden e Vanessa Aquino, da Universidade Federal do Rio Grande do Sul, possui episódio tratando sobre a Biblioteconomia Negra, com a presença das bibliotecárias Sabrina Clavé Eufrásio e Franciéle Garcês.

Existem ainda podcast que não atuam especificamente no campo da Biblioteconomia e Ciência da Informação, mas que disseminam informações étnico-raciais com temas relevantes para a comunidade negra com assuntos

\footnotetext{
2 O Biblioteco Podcast está disponível em: https://open.spotify.com/show/7shBv8zMQr6auzlYHdP8wk. Acesso: 15 out. 2021.

${ }^{3} \mathrm{O}$ podcast Farol - Conexões da Informação - pode ser acessado em: https://open.spotify.com/show/3ZMv2Ez5f7hOHJuHliDNiM. Acesso em: 15 out. 2021.
} 
como paternidade negra (AfroPai ${ }^{4}$ ), história e memória da população negra brasileira e mundial (História Preta ${ }^{5}$ ), rotina, anseios, dificuldade do mundo publicitário para pessoas negras (AfroPausa ${ }^{6}$ ), debates sociais e raciais pelo Alma Preta Jornalismo (Podcast Papo Preto ${ }^{7}$ ) e do Notícia Preta (Podcast Diálogos Pretos $^{8}$ ) com temas como transgeneridade no Brasil, mulheres negras na política, saúde mental da população negra e outros temas.

Por fim, retomamos as fontes de informação étnico-racial nas mídias sociais com o Quilombo Intelectual ${ }^{9}$, projeto com página no Facebook que dissemina informação científica étnico-racial destinada à comunidade negra, LGBTQIA+, indígena e mulheres. Esta última fonte é objeto de análise deste trabalho. Nesse sentido, o objetivo de nosso estudo é analisar o papel da página Quilombo Intelectual para a promoção das discussões sobre questões étnicoraciais e valorização intelectual da população negra, via disseminação da informação étnico-racial científica.

\section{QUILOMBO INTELECTUAL}

O Quilombo Intelectual foi criado em 2018 no Facebook e sistematicamente publica informações étnico-raciais científicas. Seu intuito é divulgar pesquisas produzidas por e a respeito da população negra, indígena, LGBTQIA+ e suas interseccionalidades. A seleção de recursos informacionais (artigos, dissertações, teses, livros) é realizada pela bibliotecária responsável. Na sequência, ela elabora artes de divulgação do material e o publica na página do Facebook e Instagram. A comunidade também indica suas produções via

\footnotetext{
${ }^{4} \mathrm{O}$ podcast AfroPai pode ser conhecido aqui: https://open.spotify.com/show/4KgYdUKOktwlkOiCmDU4BJ. Acesso em: 20 jun. 2021.

${ }^{5} \mathrm{O}$ podcast pode ser acessado em: https://open.spotify.com/show/0gkJ4Wy8wXJkJc2IZVfLyx. Acesso em: 21 jun. 2021.

6 Podcast AfroPausa pode ser encontrado aqui: https://open.spotify.com/show/3XYUTyro1XDWSQ6qxudjm5. Acesso em: 27 out. 2021.

${ }^{7}$ Podcast acessível aqui: https://www.uol.com.br/ecoa/podcast/papo-preto/. Acesso em: 27 out. 2021.

${ }^{8}$ O podcast está disponível em: https://open.spotify.com/show/5LC9S8iASJQojjtxJjjwd7. Acesso em: 27 out. 2021.

${ }^{9} \mathrm{~A}$ página pode ser conferida em: https://www.facebook.com/quilombointelectual/. Acesso em: 10 jun. 2021.
} 
mensagem privadas, as quais são analisadas e, caso se relacionem com os objetivos da página, são divulgadas nas mídias sociais (SILVA; GARCEZ; ALMEIDA, 2020).

A análise dessa página nos permitirá refletir sobre as estratégias de disseminação científica dentro do campo dos Estudos Negros, Africanos e Afrodiaspóricos, assim como dos Estudos de Gênero e Estudos Étnicos e suas interconexões com o campo biblioteconômico-informacional. Ademais, são poucas as páginas em mídias sociais que se dedicam a realizar a disseminação seletiva da informação étnico-racial em nosso país. Dessa forma, entendemos que a conscientização sobre o trabalho bibliotecário em mídias sociais pode permitir que outros projetos com este enfoque étnico-racial sejam criados e, assim, alcancem um maior número de pessoas interessadas nesses estudos.

Temos consciência, no entanto, que devido aos processos históricos que colocaram as populações negras em lugares de subordinação, desigualdades e vulnerabilidades, ainda há parte da comunidade negra que não possui acesso a computadores, notebooks, smartphones e outros dispositivos com acesso à internet. Entretanto, entendemos que este processo é moroso e precisa de políticas públicas para que tais comunidades consigam acessar a informação via tecnologias digitais. Nesse sentido, este trabalho não pretende trazer a solução para tal problema, somente apresentar estratégias que podem ser adotadas, inclusive, por quaisquer páginas de bibliotecas e organizações online.

\section{PROCEDIMENTOS METODOLÓGICOS}

Trata-se de uma pesquisa de cunho documental, exploratório e descritivo, na qual foi realizada a categorização das publicações realizadas e analisados os temas publicados pela página Quilombo Intelectual no período de 05 janeiro de 2020 a 20 junho de 2021. As publicações foram mapeadas por um perfil do Facebook sem amizades adicionadas, via página oculta. A coleta de dados foi compilada em planilha eletrônica para posterior análise dos dados.

Para a categorização das publicações coletadas, foram utilizados como modelos os estudos de Abreu (2013) e Corrêa e Silva (2017). Em seu estudo, Luana de Abreu (2013) criou categorias para analisar a informação disseminada 
no perfil na rede social Twitter da Biblioteca da Universidade Carlos III de Madrid (@biblioteca_uc3m). Na pesquisa, primeiramente foram criadas duas grandes categorias: Informativos e de Conversação; em um segundo momento, a pesquisadora as dividiu em subcategorias, a saber: a) Indicação de Links; b) Informações da Biblioteca; c) Curiosidades; d) Menções recebidas; e) Menções feitas, e f) Retweets de dados.

Em continuidade a este tipo de categorização utilizado por Abreu, mas agora com o olhar para a mídia social Facebook, a pesquisa de Elisa Corrêa e Franciéle C. Garcês da Silva (2017) elaborou nove categorias para analisar as postagens realizadas por Conselhos Regionais de Biblioteconomia brasileiros nesta mídia social, a saber: a) Citação; b) Curiosidades; c) Frases; d) Hashtags; e) Indicação de leitura; f) Indicação de Links; g) Informações de eventos; h) Informações do CRB, e; i) Outros. Esses dois estudos serviram como base para categorização da presente pesquisa, conforme detalharemos a seguir.

\section{RESULTADOS: APRESENTAÇÃO E DISCUSSÃO}

Ao total, foram analisadas 618 publicações no período enfocado. As publicações eram acompanhadas de uma legenda contendo os temas de enfoque do trabalho, o link do repositório, base de dados ou periódico no qual o trabalho poderia ser baixado, assim como a referência completa do trabalho.

Adaptando os modelos de Abreu (2013) e Corrêa e Silva (2017) apresentados nos procedimentos metodológicos desta pesquisa, as publicações foram distribuídas nas seguintes categorias: a) informação étnico-racial científica: postagens divulgando artigos, dissertações, teses, livros, monografias de especialização e trabalhos de conclusão de curso; b) quadro "Momento Griôt": no qual uma pessoa bibliotecária negra era convidada a apresentar um livro de autoria negra ou africana; c) quadro "Encontro com o autor": no qual uma autora ou autor realizava o lançamento de seu livro; d) quadro "Tenha na sua estante": publicação com indicação de obra para leitura contendo foto do(a) autor(a) e do livro divulgado (Figuras 1a, 1b, 1c, 1d). 


\section{Figura 1 - Exemplo das publicações da página Quilombo Intelectual por categorias de análise}
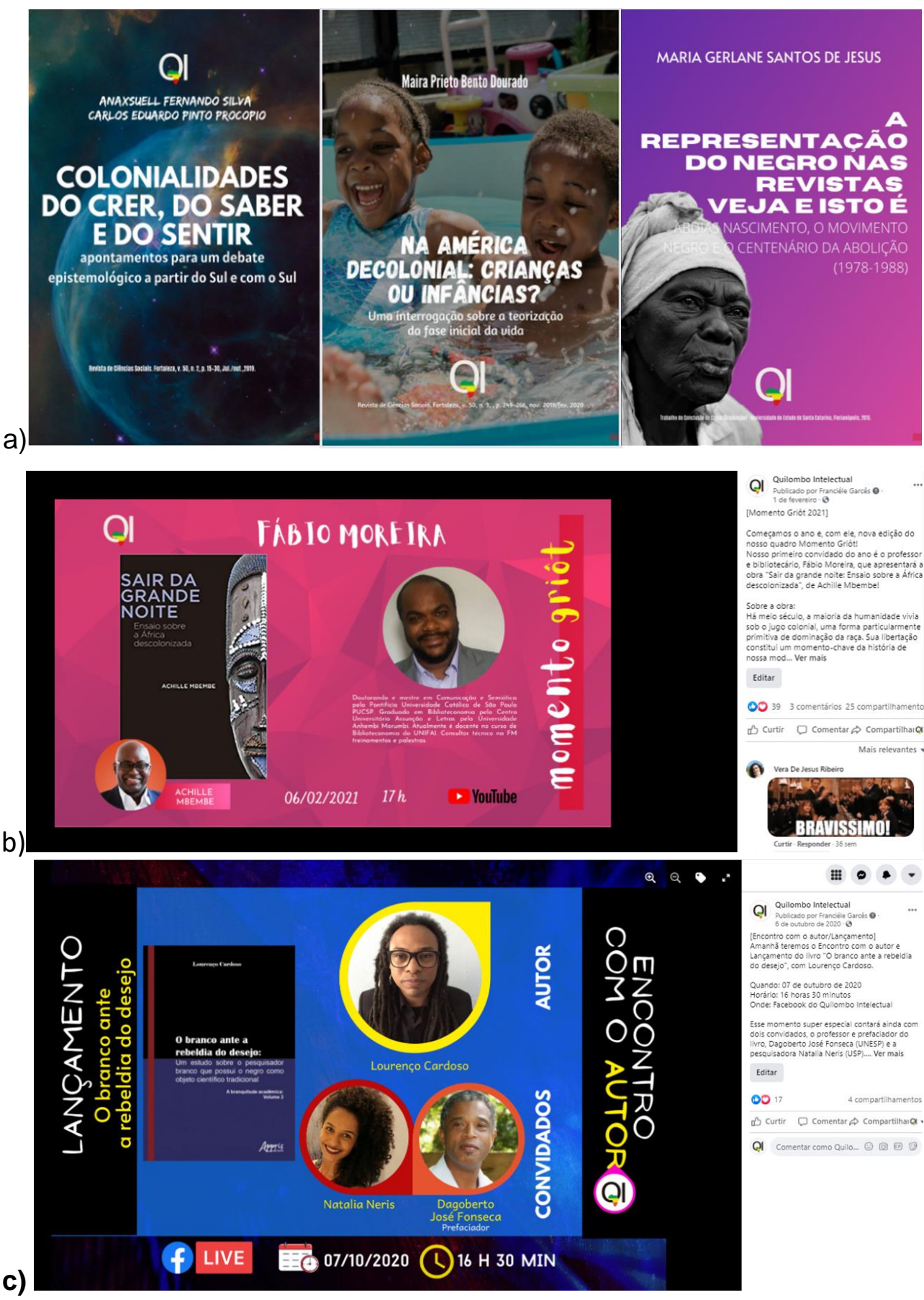

\#\# $\triangle$

QI

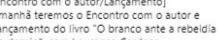

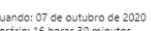

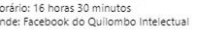

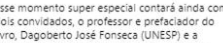

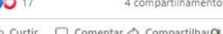

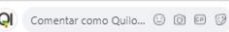
c)

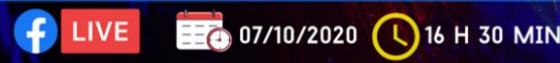




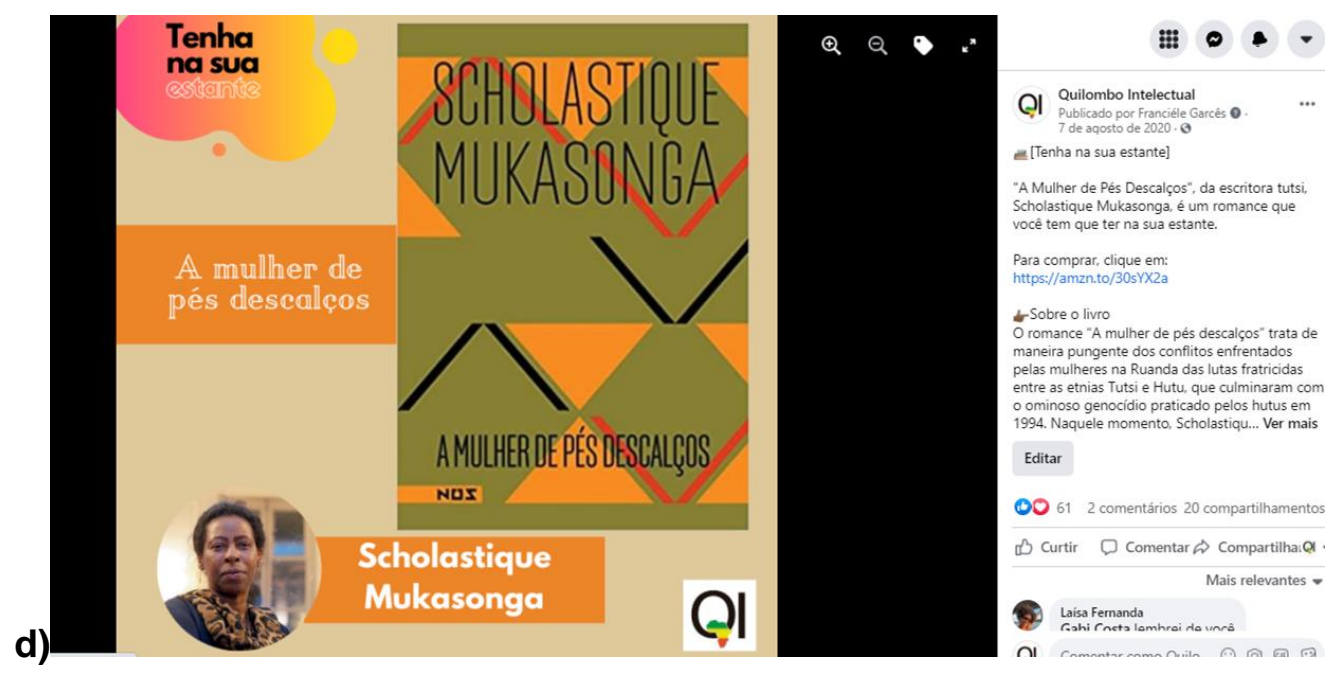

1.a) Categoria Informação étnico-racial; 1.b) Categoria Momento Griôt; 1.c) Categoria Encontro com o/a autor/a; 1.d) Categoria "Tenha na sua estante".

Fonte: Facebook Quilombo Intelectual (2021). Disponível em:

https://www.facebook.com/quilombointelectual. Acesso em: 15 out. 2021.

Figura 2 - Relação da distribuição das publicações por categorias de análise no período de janeiro de 2020 a junho de 2021

\section{Distribuição das publicações por categorias}

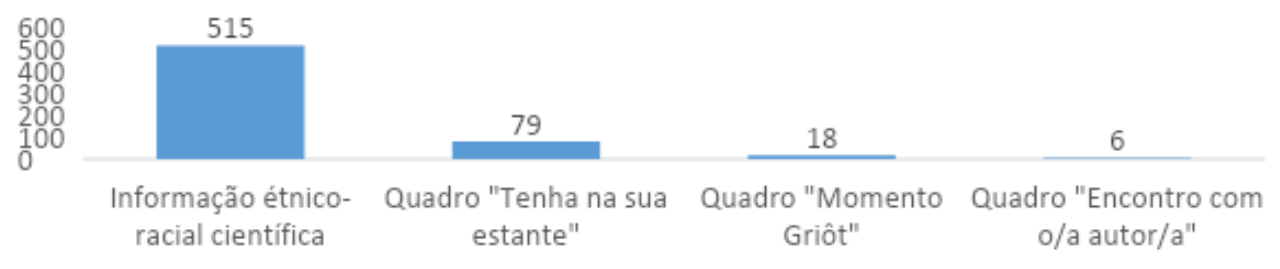

Fonte: Dados da Pesquisa (2021)

Com relação às categorias analisadas e apresentadas na Figura 1, a categoria "Informação étnico-racial científica" apresentou 83\% das publicações feitas na página no período; seguida de $13 \%$ das publicações relacionadas à categoria "Tenha na sua estante". As categorias "Momento Griôt" e "Encontro com o/a autor/a" resultaram em $3 \%$ e $1 \%$ das publicações realizadas, respectivamente. No que concerne às três últimas categorias, todas as abordagens também tinham relação com discussões das relações étnico-raciais e enfoques relacionados à população negra. 
Tabela 1 - Relação de temas mais representativos da categoria "Informação étnico-racial científica" publicados na página Quilombo Intelectual no período de janeiro de 2020 a junho de 2021.

\begin{tabular}{|l|l|l|l|}
\hline & Temas & Qtde. & $\%$ \\
\hline 1 & Estudos decoloniais, pós-coloniais e contra-coloniais & 44 & $8,8 \%$ \\
\hline 2 & Religiões e religiosidades de matriz africana & 27 & $5,4 \%$ \\
\hline 3 & Feminismo e mulherismo negros & 27 & $5,4 \%$ \\
\hline 4 & Raça, classe, gênero e interseccionalidades & 26 & $5,2 \%$ \\
\hline 5 & Construção da identidade étnico-racial & 25 & $5,0 \%$ \\
\hline 6 & Educação das relações étnico-raciais & 21 & $4,2 \%$ \\
\hline 7 & Estudos críticos da branquitude & 21 & $4,2 \%$ \\
\hline 8 & Racismo (em suas facetas institucional, recreativo, etc) & 21 & $4,2 \%$ \\
\hline 9 & Estética negra, corporalidade e identidade étnico-racial & 19 & $3,8 \%$ \\
\hline 10 & Comunicação, teatro e artes & 18 & $3,6 \%$ \\
\hline 11 & Necropolítica, genocídio e epistemicídio & 17 & $3,4 \%$ \\
\hline 12 & Estudos Africanos e da diáspora & 16 & $3,2 \%$ \\
\hline 13 & Intelectualidade e pessoas negras & 15 & $3,0 \%$ \\
\hline 14 & Epistemologias africanas, negras e afrodiaspóricas & 14 & $2,8 \%$ \\
\hline 15 & Formação e prática docente & 11 & $2,2 \%$ \\
\hline
\end{tabular}

Fonte: Dados da pesquisa (2021)

$\mathrm{Na}$ Tabela 1, apresentamos a relação de 15 temas com maior número de postagens publicadas dentro da categoria "Informação étnico-racial científica" no período de análise. Ao total, foram subcategorizados 55 temas abordados. Seguindo a sequência de principais temas e seus enfoques em pesquisas científicas, apresentaremos exemplos de abordagens enfocadas, a seguir. No que se refere aos Estudos Decoloniais, Pós-coloniais e Contra-coloniais, as pesquisas se relacionavam à colonialidade do saber, colonialidade do ser e do poder, movimentos contra-coloniais em África, opção decolonial, decolonialidade e educação, dentre outros. Quanto aos estudos sobre Religiões e religiosidades de matriz africana estes abordavam a discussão da intolerância religiosa em diversos espaços como trabalho e educação; crianças e sua vivência em terreiros; o calundu, umbanda, candomblé e outros enfoques. As pesquisas sobre feminismo e mulherismos negros enfocavam no movimento feminista negro, nos estudos mulheristas, a construção da "mulata" e a racialidade, etc. Por fim, o estudo identificou que as pesquisas que interseccionavam raça, classe e gênero abordavam as esferas do trabalho, do ensino superior, nos processos de contratação, o contexto da educação de crianças negras e outras em situação de vulnerabilidades; o cárcere e as relações raciais e de gênero, entre outras 
pesquisas divulgadas.

Para além dos 15 temas apresentados, os outros temas se relacionavam aos Estudos Indígenas, Filosofia africana, ações afirmativas, movimentos sociais negros, literatura africana e afro-brasileira, capoeira e saberes ancestrais, as áreas da Física, Química, Biologia, Geografia e a educação das relações étnicoraciais, Afrocentricidade, Psicologia, negritude e identidade, Escravidão, período colonial e abolição da escravidão, Estudos Interculturais, Estudos jurídicos e do Direito, Lei Federal № 10.639/2003; outros feminismos como o islâmico, subalternos e decoloniais, Teorias críticas feminista e de raça, Biblioteconomia Negra, Diversidade étnico-racial, Maternidade negra, Masculinidades negras, Antirracismo, Estudos ambientais e sustentáveis, Epistemologias comunitárias, Docência e cárcere, Estudos de tradução, Juventude negra e subjetividades, entre outros.

A partir das abordagens divulgadas acima, podemos refletir sobre a gama de possibilidades de pesquisa científica que engloba as populações negras e assuntos correlatos. Os resultados evidenciam as mídias sociais como meio de comunicação direta com aquelas pessoas que buscam informação étnico-racial de cunho científico. Apontou ainda, a importância de disseminar os materiais informacionais contidos em bases de dados, repositórios institucionais e periódicos científicos respeitando os direitos autorais e encaminhando as pessoas interessadas aos locais de armazenamento e preservação destes recursos. Ademais, permitiu evidenciar a práxis bibliotecária e as habilidades profissionais desenvolvidas, as quais permitem realizar a seleção, organização e a disseminação seletiva para o público-alvo da página. Por fim, o estudo demonstrou possibilidades de promoção dos estudos sobre raça, gênero, classe, de(s)colonialidades, feminismos e mulherismos, aspectos religiosos, dentre outros enfoques relacionados à questão racial.

\section{CONSIDERAÇÕES FINAIS}

Este estudo realizou a análise das publicações da página Quilombo Intelectual visando identificar seu papel para a valorização da população negra e discussões sobre as questões étnico-raciais no Facebook. Os dados coletados 
demonstraram as estratégias adotadas para divulgação das informações étnicoraciais científicas, as quais foram complementadas pelas ações criadas pela página com o mesmo enfoque, a saber: "Momento Griôt, "Encontro com o autor" e "Tenha na sua estante".

Concluímos, assim, que a página Quilombo Intelectual promove fontes de informação científica e de cunho étnico-racial, as quais corroboram para o conhecimento do estado da arte sobre o tema em diversas áreas do conhecimento; a promoção da identidade étnico-racial da população negra; o conhecimento dos aspectos históricos, culturais, políticos e educacionais da referida população; o combate às informações pré-concebidas ou equivocadas, via ciência; e, por fim, valoriza pesquisadores(as) negros(as) e de outros pertencimentos étnicos que abordam e discutem as relações étnico-raciais.

\section{AGRADECIMENTOS}

Agradecemos à Coordenação de Aperfeiçoamento de Pessoal de Nível Superior (CAPES) pela concessão de bolsa de Doutoramento à primeira pessoa autora - Código de Financiamento 001 - e à Fundação de Amparo à Pesquisa do Estado da Bahia (FAPESB) pela concessão de bolsa de Mestrado à segunda pessoa autora.

\section{REFERÊNCIAS}

ABREU, L. Marketing digital e o fator whuffie de bibliotecas no Twitter. 2013. 76 f. Trabalho de Conclusão de Curso (Graduação em Biblioteconomia) Universidade do Estado de Santa Catarina, Centro de Ciências Humanas e da Educação, Curso de Biblioteconomia, Florianópolis, 2013.

BRASIL. Presidência da República. Lei no 10.639 de 09 de janeiro de 2003. Diário Oficial da União. Brasília, 2003.

BRASIL. Presidência da República. Lei no 11.645, de 10 de março de 2008. Diário Oficial da União. Brasília, 2008.

CARVALHO, W. M.; REZENDE, A.; GOMES, G. M. R. Fontes de informação especializada em africanidades. PontodeAcesso, Salvador, v. 13, n. 1, p. 174201, ago. 2019. Disponível em: 

negra

https://periodicos.ufba.br/index.php/revistaici/article/view/30464. Acesso em: 15 out. 2021.

CORRÊA, E. D.; SILVA, F. C. G. Presença Digital dos Conselhos Regionais de Biblioteconomia do Brasil no Facebook. Perspectivas em Ciência da Informação, Belo Horizonte, v. 22, p. 16-32, 2017.

GOMES, E. Afrocentricidade: discutindo as relações étnico-raciais na biblioteca. Revista ACB: Biblioteconomia em Santa Catarina, Florianópolis, v. 21, n. 3, p. 738-752, 2016. Disponível em:

http://hdl.handle.net/20.500.11959/brapci/71694. Acesso em: 15 out. 2021.

OLIVEIRA, H. P. C.; AQUINO, M. A. O conceito de informação etnicorracial na ciência da informação. Liinc em Revista, Rio de Janeiro, v. 8, n. 2, p. 466-491, 2012. DOI: 10.18617/liinc.v8i2.453. Disponível em: http://revista.ibict.br/liinc/article/view/3336/2943. Acesso em: 15 out. 2021.

PAIVA, E. B. Conceituando fonte de informação indígena. Informação \& Sociedade: Estudos, João Pessoa, v. 24, n. 1, p. 61-70, 2014.

PORTER, D. B. A library on the Negro. The American Scholar, Washington (D.C), v. 7, n. 1, p. 115-117, 1938.

SANTOS, T. H. N.; AQUINO, M. A. Entre os estudos culturais e a Ciência da Informação: fontes de informação étnico-raciais. Informação \& Informação, Londrina, v. 21, n. 1, p. 29-55, 2016.

SILVA, A. S.; KARPINSKI, C. O contexto informacional dos núcleos de estudos afro-brasileiros: analisando o Facebook como uma fonte de informação étnicoracial. Liinc Em Revista, Rio de Janeiro, v. 14, n. 2, p. 276-294, nov. 2018. Disponível em: https://doi.org/10.18617/liinc.v14i2.4288. Acesso em: 15 out. 2021.

SILVA, D. M. F.; FERREIRA, R. G. S. O uso do podcast na disseminação de informações étnico-raciais. Revista Folha de Rosto, Juazeiro do Norte, v. 5, n. especial, p. 109-117, 2019. Disponível em:

http://hdl.handle.net/20.500.11959/brapci/136585. Acesso em: 15 out. 2021.

SILVA, F. C. G.; GARCEZ, D.; ALMEIDA, B. Quilombo Intelectual e a promoção da autoria e protagonismo negros: a experiência do Momento Griôt com pessoas bibliotecárias negras. In: SILVA, F. C. G. (org.). Bibliotecári@s negr@s: Pesquisas e experiências de aplicação da Lei 10.639/2003 na formação bibliotecária e nas bibliotecas. Florianópolis: Rocha Gráfica e Editora, 2020. p. 381-404.

SILVA, F. C. G. Colonialidade do saber e dependência epistêmica na Biblioteconomia: reflexões necessárias. In: CARDONA, N. D.; SILVA, F. C. G. (org.). Epistemologias Latino-Americanas na Biblioteconomia e Ciência da 
Informação: contribuições da Colômbia e do Brasil, Florianópolis: Rocha Gráfica e Editora, 2020.

SILVA, L. K. R; AQUINO, M. A. Fontes de informação na Web: apropriação, uso e disseminação da informação étnico-racial no movimento negro da Paraíba. Transinformação, Campinas, v. 26, n. 2, p. 203-212, 2014.

TONIN, J. H. C.; SOUZA, E. D. A seleção de fontes de informação em bibliotecas prisionais do estado de Alagoas: do direito às condições de acesso do usuário apenado. Ciência da Informação em Revista, Maceió, v. 1, n. 1, p. 47-63, 2014.

VALE, M. A.; VITORINO, E. V. Fontes de informação online para comunidade LGBT+. Revista Brasileira de Biblioteconomia e Documentação, São Paulo, v. 15, p. $50-71,2019$.

\title{
QUILOMBO INTELECTUAL, SCIENTIFIC ETHNIC- RACIAL INFORMATION AND THE INTELLECTUAL VALUE OF THE BLACK POPULATION
}

\begin{abstract}
Objective: Analyze the role of the Quilombo Intelectual page in promoting discussions on ethnic-racial issues and intellectual valuation of the black population, via the dissemination of scientific ethnic-racial information. Methodology: This research is documentary, exploratory and descriptive and analyzes the posts published on the Quilombo Intelectual page on Facebook from January 2020 to June 2021. Results: In total, we collected and analyzed 618 publications, according to the models of Abreu (2013) and Corrêa and Silva (2017). From the models, four main categories were elaborated, namely: ethnic-racial scientific information and the tables "Momento Griôt", "Encontro com o/a autor/a" and "Tenha na sua estante". Conclusions: The Quilombo Intelectual page promotes scientific and ethnic-racial sources of information, which corroborate to:: (i) knowledge of the state of the art on the subject in various areas of knowledge; (ii) the promotion of ethnic-racial identity of the black population; (iii) knowledge of the historical, cultural, political and educational aspects of that population; (iv) the fight against preconceived or mistaken information, via science; (v) and, finally, it values black researchers and researchers from other ethnic backgrounds who approach and discuss ethnic-racial relations..
\end{abstract}

Descriptors: Quilombo Intelectual. Facebook. Scientific ethnic-racial information. Black population.

\section{QUILOMBO INTELECTUAL, INFORMACIÓN CIENTÍFICA ÉTNICO-RACIAL Y EL VALOR INTELECTUAL DE LA POBLACIÓN NEGRA}




\section{RESUMEN}

Objetivo: Analizar el papel de la página Intelectual Quilombo en la promoción de discusiones sobre temas étnico-raciales y la valoración intelectual de la población negra, mediante la difusión de información científica étnico-racial. Metodología: Se trata de una investigación documental, exploratoria y descriptiva, en la que se analizaron las publicaciones en la página de Facebook Quilombo Intellectual desde enero de 2020 a junio de 2021. Resultados: En total, se recolectaron y analizaron 618 publicaciones, categorizadas según los modelos de Abreu (2013) y Corrêa y Silva (2017). A partir de los modelos se elaboraron cuatro categorías principales, a saber: información científica étnico-racial y las tablas "Momento Griôt", "Encontro com o/a autor/a" y "Tenha na sua estante". Conclusiones: La página de Quilombo Intelectual promueve fuentes de información científicas y étnico-raciales, que corroboran: (i) el conocimiento del estado del arte sobre el tema en diversas áreas del conocimiento; (ii) la promoción de la identidad étnico-racial de la población negra; (iii) conocimiento de los aspectos históricos, culturales, políticos y educativos de esa población; (iv) combatir la información preconcebida o errónea, a través de la ciencia; (v) y, finalmente, valora a los investigadores negros e investigadores de otros orígenes étnicos que abordan y discuten las relaciones étnico-raciales.

Descriptores: Quilombo Intelectual. Facebook. Información científica étnico-racial. Población negra.

Recebido em: 30.10 .2021

Aceito em: 27.12.2021 